Research Paper

\title{
A Framework of Location-Based Advertising Effectiveness: Perspectives of Perceived Value and Satisfaction
}

\author{
Xuan Cu Le* and Tran Hung Nguyen \\ Department of Economic Information System \& Electronic Commerce, Thuongmai University, \\ Vietnam \\ *Corresponding author: cu.lx@tmu.edu.vn
}

\begin{abstract}
The power of innovative positioning technology and the prevalence of mobile handheld devices have benefited prominently the interactions between businesses and consumers via modern interactive marketing channels. Location-based advertising (LBA) is a salient instance. It is imperative for marketers to understand thoroughly a mechanism of consumers' value perceptions in LBAs and the motivations for their buying decisions to advertised brands. A research model is constructed based on the Choice Value Model (CVM) to identify a range of important factors navigating perceived value, satisfaction and behavioral intentions toward LBAs. A survey of 306 mobile users in Vietnam was gathered. The findings revealed that content quality generates the strongest signal for predicting perceived value, whereas advertising perception is investigated to be the lowest indicator. Moreover, perceived value closely relates to satisfaction, continuance intention and buying inclination. Otherwise, satisfaction is unveiled as a necessary catalyst to quicken buying inclination in LBAs. Finally, theoretical implications and hints for Asian business are discussed.
\end{abstract}

Keywords: Perceived value, Contextualization, Content quality, Satisfaction, Choice value model. 


\section{Introduction}

Advanced technologies and cell-phones have paid attention from users and businesses due to their pervasiveness and even their domination in the daily lives. According to Statista (2021), the estimated figure for smart-phone users in 2021 surpasses 6.378 billion. Approximately 5.13 billion users $(66.53 \%)$ worldwide own mobile devices today (Bankmycell, 2019). The number of smartphone users is forecasted to further grow to 7.516 billion by 2026. China, India and United States hold the highest development of smart-phone usage with the figures for 775 million, 387 million and 235 million people respectively in 2019. Besides, Vietnam has become a potential smartphone market of well-known producers such as Apple, Samsung, Oppo and domestic brands due to the rapid increase in young and middle-class customers' expenditure and digital media consumption. Indeed, $72 \%$ of Vietnamese users have had smart-phone ownership (Appota, 2018). The usage of mobile devices is changing dramatically shopping behavior, interactions and service usage, specifically $25 \%$ of Vietnamese population participating mobile-related activities.

With the impressive growth of smartphone market, Vietnam is highly appreciated as a potential milieu of online shopping via mobile advertising. 53\% of Vietnamese customers express their willingness to purchase products/services via cell-phones, but firms' investment in mobile advertising stood at 78 million USD (about $36.6 \%$ of total advertising investment) in 2017 (Appota, 2018). It implies that firms' readiness remains low because there is a lack of the insightful understanding of consumers' wants, judgment and behaviors toward mobile advertising. A further reason is that the selection of an effective mobile advertising approach is necessary for firms to not only enhance consumer awareness of brands and trigger shopping behavior, but also boost competitive advantage in the advertising market. The introduction of LBA has received attention from managers and scholars. LBA is understood as the distribution of mobile advertisements to users nearby vendors' point-of-sales at the real time and in the relevant context due to positioning technologies such as GPS, A-GPS and geo-fencing. Albeit academic studies on mobile advertising have conducted (Martins et al., 2019), little is adequately considered whether perceived value motivates continuance intention and buying inclination in the LBA scenario. Moreover, although this topic has drawn an increasing attention of researchers from advanced-technology countries like Singapore, Japan, Korea and China, a little research has conducted empirically in developing countries like Vietnam. Therefore, this research aims to test a hypothetical model of perceived value and behavioral responses in the growing phase of LBAs in Vietnam.

Three research questions are drawn as follows:

1. How do customers express perceived LBA value?

2. Does perceived value motivate satisfaction, continuance intention and buying inclination?

3. Does satisfaction significantly influence continuance intention and buying decisions?

Extant studies have employed various well-established theories of behavioral responses such as Ducoffe's web-advertising model (Martins et al., 2019), Uses and Gratifications (U\&G) and Theory of Planned Behavior (TPB) (Le and Wang, 2021) to explore how behavioral responses are shaped in the marketing industry, whilst the Choice Value 
Model of Sheth et al. (1991) is considered elaborately as a theoretical underpinning to identify important dimensions for predicting advertising value, satisfaction and buying inclination in this study. Furthermore, satisfaction and continuance intention will be examined to demonstrate LBA effectiveness.

The major contributions are offered in some ways. First, this work offers an overarching picture regarding a mechanism of customer inclination to purchase products/services after viewing LBAs via smartphones. For this contribution, satisfaction and perceived value are facilitators of buying inclination in LBAs. Second, current study unveils how perceived value is formulated through the influence of the crucial antecedents from CVM. Third, customers' continuance intention and buying inclination are significantly determined by perceived value and satisfaction. Generally, this work seems to be the first to include perceived value, satisfaction, continuance intention and buying inclination in the LBA setting and in a developing country like Vietnam. Lastly, pinpointing the variables that affect perceived value, satisfaction and behavioral intentions (i.e., continuance intention and buying inclination) would enable marketers and vendors to apply the appropriate, effective advertising tactics and implement efficient operations for improving customer satisfaction, prolonged usage and buying decisions by manipulating the independent variables in a competitive advertising market in Vietnam.

\section{Literature Review}

\section{Choice Value Model (CVM)}

The CVM of Sheth et al. (1991) is utilized to identify motivations for perceived value and the impact of perceived value on buying inclination in LBAs. CVM attempts to clarify the reasons for consumers' perceptions and their evaluation of the utility of traditional media (Sheth et al., 1991), health information seeking via mobile phones (Deng et al., 2015), mobile financial services (Omigie et al., 2017) and mobile marketing (Huang et al., 2019). There are five fundamental antecedents in the original model, including functional value, conditional value, epistemic value, social value and emotional value. Particularly, functional value depicts perceived benefits of the capacity for functional performance. For LBAs, it contains the main aspects of advertising perceptions, namely ease to use, understandable and content display. Second, conditional value details perceived utility acquired by LBAs as the result of a specific situation facing the choice maker. It depends on the provision of time, space and technology innovation. Third, epistemic value in LBAs reflects the extent to when users fulfill satisfaction from advertisements and arouse curiosity to experience modern shopping from information acquirement. Fourth, social value is perceived from advertisements' capacity to improve social self-concept. Lastly, emotional value delineates the feelings and affective states from advertisements. For LBAs, this study suggests that entertainment and irritation demonstrate emotional value for navigating advertising value. Entertainment posits the fun or pleasure via the usage of advertisements, whereas irritation reflects the degree to which customers feel messy and irritating to advertisements (Le and Wang, 2021). 


\section{Behavioral Intentions}

Behavioral intention delineates the subjective assessment on how individuals tend to execute a performance and it forms a connection between customers and an IS (Wong et al., 2020). In this study, behavioral intentions comprise buying inclination and continuance intention. On the one hand, buying inclination reflects customers' intention to purchase products/services via LBAs. It is used to measure advertising effectiveness and is influenced by perceived value. For instance, Lin et al. (2016) showed a strong liaison from advertising value to behavioral intentions toward LBAs (i.e., buying inclination, passing along and brand seeking). Otherwise, scholars advocated that satisfaction is an important motivator of behavioral intention. Gan and Wang (2017) formulated a mechanism of buying inclination in the social commerce context and revealed that satisfaction and buying inclination are well surmised by perceived valuerelated factors (i.e., hedonic value, social value, utilitarian and perceived risk) and satisfaction leverages customers' buying inclination. Consistent with these findings, the significant relationship between satisfaction and buying inclination was found in mobile services (Kuo et al., 2009).

On the other hand, continuance intention describes the degree to which an individual intends to continue using an IS (Bhattacherjee, 2001). Current literature denoted that continuance intention is similar to repurchase decisions because some important reasons: first, customers raise their perceptions of usefulness and utilities of an IS; second, they follow an initial adoption and purchase intention toward the IS; third, they can be affected by the initial use of the IS experience; four, they feel satisfied with the IS. Extant studies found that continuance intention is driven by perceived value and satisfaction (Poromatikul et al., 2020), expected benefits, leisure and passing time (Le, 2021), perceived usefulness and adoption intention (Bhattacherjee, 2001). Sreelakshmi and Sangeetha (2020) affirmed a significantly positive relationship between perceived usefulness and intention to reuse mobile-based payments across Indian users. Other researchers recorded that attitude and trust are the essential predictors of continued use in an IS (Asnakew, 2020). Joo et al. (2017) revealed that perceived usefulness and satisfaction play a key role in continuance intention toward digital textbooks. Leung and Chen (2019) argued that users' levels of satisfaction with health-related information platforms usage are closely related with continuance intention. After reviewing the literature and empirical results, this study presumes that continuance intention is motivated by perceived value and satisfaction in a specific LBA context.

\section{Advertising Perception}

Advertising perception depicts users' subjective thoughts about arguments in the advertising messages (Petty and Cacioppo, 1986). It involves the length and composition of an advertisement. Consumers who cognize advertisements to be clear, realistic and believable produce favorable perceptions of such advertisements (Stewart et al., 2018). Customers perceive the same advertisements differently due to their subjective assessment. Researchers agreed to a positive relationship between advertising perception and perceived value in SMS advertising (Bakr et al., 2019). Park (2020) highlighted that information perceptions (e.g., need for information) have a positive influence on information usefulness, leading to information adoption and loyalty in the electronic word-of-mouth (eWOM) context. Hence, prior studies concluded that higher levels of advertising perceptions are more likely to express 
positive attitude toward advertising messages and advertised brands, and advertising value toward mobile advertising. Therefore, the following hypothesis is framed:

H1 Advertising perception is positively associated with perceived value.

\section{Contextualization}

Contextualization provides advertisers with ample opportunities of contributing precisely mobile advertisements to target customers based on the benefits of spatial, temporal conditions and advanced technology (Le and Wang, 2020). The location of stores significantly influences their sales. Accordingly, contextualization leads to the enhancement of advertising value (Lin and Bautista, 2020). In the traditional context, Thaichon et al. (2019) substantiated that location plays an indispensable role in purchase intention at fast food stores. Other scholars illustrated that contextualization seems important to contribute significantly to advertising effectiveness in the LBA setting (Feng et al., 2016). Therefore, LBAs with highly-relevant and timely messages intend to disclose to favorable judgment, adoption and purchase tendency of customers. Thus, the following hypothesis is constructed:

H2 Contextualization is positively associated with perceived value.

\section{Content Quality}

Content quality refers to advertisers' capability to match users' needs relating qualified and proper information (Bakr et al., 2019). In this study, content quality delineates the quality of advertising content and advertising form that LBAs provide. It is measured by several salient features, consisting of accuracy, relevance, completeness and timeliness of information (Cheng, 2020). Scholars advocated firmly the pivotal role of content quality in justifying valuable advertisements (Ducoffe, 1995). Indeed, the appropriate, relevant and useful information improves source credibility of social media in the COVID-19 pandemic (Nguyen and Le, 2021). Moreover, past studies showed the strong link between content quality and perceived value in SMS advertising (Bakr et al., 2019) and smart-phone advertising (Martins et al., 2019). Additionally, scholars argued that information quality boosts perceived usefulness toward cloud-based hospital information system (Cheng, 2020) and eWOM (Park, 2020). Consistent with these investigations, this study surmises that when advertisers disseminate highqualified messages to mobile users and these messages are designed to fulfill their needs, they will express favorable judgment and perceive LBAs to be a useful means. Hence, the following hypothesis is drawn:

H3 Content quality is positively associated with perceived value.

\section{Social Involvement}

Social involvement refers to the connection with other individuals who are willing to share their experience and encourage users in order to perform a specific behavior (Heitzmann and Kaplan, 1988). It characterizes mental supports, the creation of better impression or approval to advertisements (Gan and Wang, 2017). Social involvement allows consumers to acquire more useful information (Ha et al., 2014). Existing mobile advertising literature indicated the important role of social involvement in increasing 
advertising effectiveness (Wang and Genç, 2019). Le and Wang (2020) documented that social involvement factors (i.e., social value and interactivity) promote attitude toward LBAs. Generally speaking, consumers perceive higher levels of social involvement, they would likely to realize more valuable advertisements. Therefore, the following hypothesis is given:

H4 Social involvement is positively associated with perceived value.

\section{Entertainment}

Entertainment is related to the non-functional benefits (Heijden, 2004). It is captured by hedonic motivation in Unified Theory of Acceptance and Use of Technology (UTAUT) (Wong et al., 2020), pleasure and arousal (Zhu et al., 2017) and enjoyment (Le and Wang, 2021). It is viewed as the psychological and emotive experiences of individuals, which can be created by cognitive mechanisms and individual traits (Magni et al., 2010). Zhu et al. (2017) found that pleasure and arousal indicate emotional motivations and are influenced by perceived accuracy and transaction cost reduction in LBAs. In the advertising setting, entertainment illustrates the emotional motivation via advertising usage. It plays an important role in customers' adoption intention. Wong et al. (2020) reported that it is a crucial predictor of behavioral intention toward mobile Internet. Entertainment increases consumers' attraction as advertisements provide pleasurable and interesting experience (Wang and Genç, 2019). Moreover, entertainment navigates significantly perceived value in web advertising (Ducoffe, 1995). Researchers investigated that it influences positively advertising value in SNS advertising (Ha et al., 2014) and LBA (Lin and Bautista, 2020). This can be possibly explained that if customers recognize advertisements to have enjoyment and fun, their acceptability toward such advertisements can be significantly stimulated. It is argued that customers perceive LBAs to be valuable and useful when they have pleasure and enjoyment from emotional and aesthetic motivations. Thus, the following hypothesis is postulated:

\section{H5 Entertainment is positively associated with perceived value.}

\section{Irritation}

Irritation is understood as the negative, impatient and displeasing feelings of individuals toward advertisements (Morimoto and Chang, 2006). It indicates irritation and annoyance in LBAs. Irritation reduces advertising effectiveness based on users' negative emotions toward smartphone advertising (Martins et al., 2019). Some major reasons lie behind this negative impact. First, an overwhelming amount of information via some annoying techniques annoys consumers (Ducoffe, 1995). Second, the poor content quality causes irritation (Lin and Bautista, 2020). Another reason is the dispersion of advertisements without consumers' permission and necessity (Ha et al., 2014). Le and Wang (2021) demonstrated that irritation is an inhibitor of attitude toward LBAs. Previous studies reported that irritation has an adverse effect on perceived value in smartphone advertising (Martins et al., 2019) and mobile SNS advertising (Ha et al., 2014). Customers are likely to adopt behavioral intentions and buying inclination in LBAs if it is not intrusive and irritating (Wang and Genç, 2019). Hence, the following hypothesis is established: 
H6 Irritation is negatively associated with perceived value.

\section{Advertising Value}

Advertising value reflects the worth of advertisements to consumers (Ducoffe, 1995). When advertisements are assessed to be valuable and closely related to customer demands, they will feel satisfied and continue using the advertisements (Hsiao and Chang, 2014). Le (2021) investigated that customers express their satisfaction with social media when they perceive its services as being expected benefits. Likewise, extant research affirmed that perceived value promotes satisfaction in mobile financial apps, which leads to continuous usage toward online banking services (Poromatikul et al., 2020). The strong impact from perceived value to satisfaction was unveiled in cloud-based hospital information system (Cheng, 2020). Furthermore, perceived value acts a pivotal role in boosting consumers' shopping inclination in LBAs (Lin et al., 2016) and electronic vehicles (Nguyen, 2021). Kim and Han (2014) also supported the significantly positive correlation between perceived value and buying inclination toward mobile advertising. This study argues that customers' purchase decisions are induced when they show favorable judgment toward LBAs. Therefore, the following hypotheses are developed:

H7 Perceived value is positively associated with satisfaction.

H8 Perceived value is positively associated with continuance intention.

H9 Perceived value is positively associated with buying inclination.

\section{Satisfaction}

Satisfaction is understood as the psychological state resulting when the emotion surrounding disconfirmed expectations is coupled with consumers' prior feelings about the consumption experience (Oliver, 1980). It delineates consumers' assessment upon their expectations and demands. It reflects consumers' positive emotional states when using mobile services (Hsu and Lin, 2016). Continuance intention refers to behavioral tendency to prolong the LBA usage, whilst buying inclination depicts consumers' intention to purchase advertised products/services. The positive effect of satisfaction on continuance intention was confirmed in previously empirical studies in mobile advertising (Hsiao and Chang, 2014), mobile instant messaging (Oghuma et al., 2016) and cloud-based hospital information system (Cheng, 2020). Besides, current literature showed the close correlation between satisfaction and buying inclination in social commerce (Gan and Wang, 2017) and mobile services (Kuo et al., 2009). Thus, the following hypotheses are formulated:

H10 Satisfaction is positively associated with continuance intention.

H11 Satisfaction is positively associated with buying inclination. 
Figure 1: Research Model

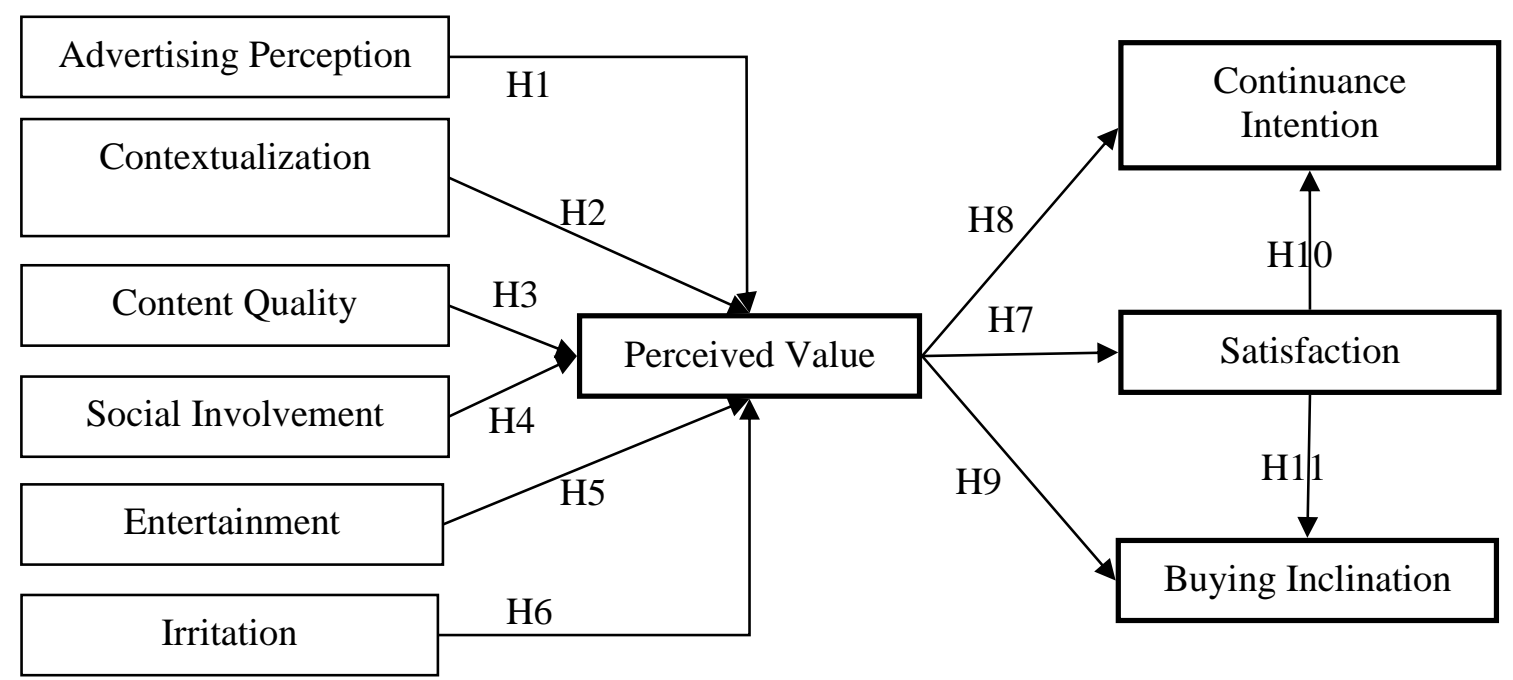

Figure 1 portrays the research framework. In the LBA context, it is surmised that perceived value is motivated by six independent variables (i.e., advertising perception, contextualization, content quality, social involvement, entertainment and irritation). In addition, satisfaction and behavioral intentions (i.e., continuance intention and buying inclination) are employed to evaluate the effectiveness of LBAs from a consumer perspective.

\section{Methodology}

A survey questionnaire was designed to examine the hypothetical model. Pre-test and pilot test were applied to test whether all items actually measure constructs. First, pretest was conducted to identify some problems about the questionnaire's format, length and content. Second, the pilot survey was developed to evaluate the questionnaire's suitability. A small sample with 25 participants was recruited. Initial result indicated that coefficient alpha values of all constructs exceeded 0.7 .

Data collection underwent four weeks. This study applied a convenience sampling method. Based on national language, questionnaire was translated into Vietnamese. To ensure that all participants understand LBAs, its definition and its examples were illustrated before responding to the survey. Finally, 306 respondents were deemed for the validated sample after initial screening.

The proposed research model comprises 10 constructs and 32 items used to measure these constructs. Multiple items for each construct were developed based on an extensive literature review. Respondents evaluated all items with five-point Likert scales, ranging from 1 - for "strongly disagree" through 3 - for "neutral" to 5 - for "strongly agree".

Four items for advertising perception were adapted from Beltramini (1988) and Slater and Rouner (1996). Contextualization with three items was adapted from Merisavo et al. (2007) and Le and Wang (2020). Whereas three items of content quality were 
adapted from Handayani et al. (2017), four items for measuring social involvement were adapted from Calder et al. (2009). Regarding emotion value, entertainment was adapted from Nysveen et al. (2005) and irritation with three items was adapted from Tsang et al. (2004). Three items for perceived value were adapted from Ducoffe (1995). We developed satisfaction with three items with the reference to the scales adapted from Bhattacherjee (2000). Three items for measuring continuance intention were adapted from Bhattacherjee (2001). Measurement for four items of buying inclination was adapted from Venkatesh and Davis (2000).

\section{Results}

Table 1: Respondents' Demographic Characteristics

\begin{tabular}{llcc}
\hline \multicolumn{1}{c}{$\begin{array}{c}\text { Demographic } \\
\text { Variables }\end{array}$} & \multicolumn{1}{c}{ Category } & Frequency & Percentage \\
\hline Gender & Male & 141 & 46.1 \\
& Female & 165 & 53.9 \\
Age (years old) & $18-24$ & 156 & 51 \\
& $25-30$ & 81 & 26.5 \\
Highest Education & 31 and above & 69 & 22.5 \\
Level & High school & 18 & 5.9 \\
& Bachelor & 213 & 69.6 \\
Current Area of & Master & 61 & 20 \\
Occupation & Doctoral & 14 & 4.5 \\
& Student & 178 & 58.2 \\
& Administrations & 51 & 16.7 \\
& Business & 42 & 13.7 \\
Smartphone usage & Freelance & 15 & 4.9 \\
(years) & Unemployment & 8 & 2.6 \\
& Others & 12 & 3.9 \\
& 3-5 & 31 & 10.1 \\
& Above 5 & 122 & 39.9 \\
\hline
\end{tabular}

\section{Demographic Background}

Demographic characteristics of the respondents are presented in Table 1. Participants comprised 141 males (46.1\%) and 165 females (53.9\%). Majority of respondents were in the age range of $18-24$ years old (51\%), followed by $25-30$ years old $(26.5 \%)$ and 31 and above $(22.5 \%)$. More than half of the respondents had bachelor $(69.6 \%)$; the remainder of the respondents were master (20\%), high school level (5.9\%) and doctoral (4.5\%). Majority of respondents were students $(58.2 \%)$, followed by administrations (16.7\%), business (13.7\%), freelance (4.9\%), unemployment $(2.6 \%)$ and others $(3.9 \%)$. A half of the participants have experienced using smartphones more than 5 years; the remainder of the respondents were $3-5$ years $(39.9 \%)$ and below 3 years $(10.1 \%)$. 


\section{Evaluation of Measurement Model}

First, the reliability of questionnaire is evaluated. Cronbach's alpha of all constructs exceeded 0.8, ranging from 0.843 (advertising perception) to 0.951 (social involvement), therefore illustrating the evidence of acceptable reliability (see Table 2).

Second, SPSS 22 is used to conduct EFA applying principal axis factoring with Promax rotation to test construct validity of measures. The KMO was $0.860(>0.5)$ and Bartlett's test was significant at 0.000 . Based on the role of Eigen value exceeds, factors were extracted and had factor loadings (>0.5) (depicted in Table 2), thus suggesting a good construct validity.

Table 2: Measurement Model

\begin{tabular}{|c|c|c|c|c|c|}
\hline Variable & Item & Loading & $\begin{array}{c}\text { Cronbach's } \\
\text { Alpha }\end{array}$ & AVE & $\mathbf{C R}$ \\
\hline Advertising & ADV1 & 0.790 & \multirow{3}{*}{0.843} & \multirow{3}{*}{0.642} & \multirow{3}{*}{0.843} \\
\hline \multirow[t]{2}{*}{ Perception } & ADV2 & 0.816 & & & \\
\hline & ADV3 & 0.802 & & & \\
\hline \multirow[t]{3}{*}{ Contextualization } & $\mathrm{PCO} 1$ & 0.772 & \multirow{3}{*}{0.860} & \multirow{3}{*}{0.672} & \multirow{3}{*}{0.859} \\
\hline & $\mathrm{PCO} 2$ & 0.923 & & & \\
\hline & $\mathrm{PCO} 3$ & 0.762 & & & \\
\hline \multirow{4}{*}{ Content Quality } & CON1 & 0.830 & \multirow{4}{*}{0.863} & \multirow{4}{*}{0.617} & \multirow{4}{*}{0.865} \\
\hline & CON2 & 0.862 & & & \\
\hline & CON3 & 0.750 & & & \\
\hline & CON4 & 0.667 & & & \\
\hline \multirow{4}{*}{ Social Involvement } & SOC1 & 0.882 & \multirow{4}{*}{0.951} & \multirow{4}{*}{0.829} & \multirow{4}{*}{0.951} \\
\hline & SOC2 & 0.934 & & & \\
\hline & SOC3 & 0.913 & & & \\
\hline & SOC4 & 0.913 & & & \\
\hline \multirow[t]{3}{*}{ Entertainment } & ENT1 & 0.821 & \multirow{3}{*}{0.890} & \multirow{3}{*}{0.732} & \multirow{3}{*}{0.891} \\
\hline & ENT2 & 0.860 & & & \\
\hline & ENT3 & 0.888 & & & \\
\hline \multirow[t]{3}{*}{ Irritation } & IRR1 & 0.906 & \multirow{3}{*}{0.932} & \multirow{3}{*}{0.821} & \multirow{3}{*}{0.932} \\
\hline & IRR2 & 0.922 & & & \\
\hline & IRR3 & 0.860 & & & \\
\hline \multirow[t]{3}{*}{ Perceived Value } & VAL1 & 0.804 & \multirow{3}{*}{0.928} & \multirow{3}{*}{0.817} & \multirow{3}{*}{0.930} \\
\hline & VAL2 & 0.980 & & & \\
\hline & VAL3 & 0.877 & & & \\
\hline Continuance & USE1 & 0.858 & \multirow{3}{*}{0.915} & & \\
\hline \multirow[t]{2}{*}{ Intention } & USE2 & 0.890 & & 0.784 & 0.916 \\
\hline & USE3 & 0.907 & & & \\
\hline Satisfaction & SAT1 & 0.825 & & & \\
\hline & SAT2 & 0.909 & 0.912 & 0.776 & 0.912 \\
\hline & SAT3 & 0.905 & & & \\
\hline Buying Inclination & BUY1 & 0.887 & & & \\
\hline & BUY2 & 0.907 & 0.915 & 0.782 & 0.915 \\
\hline & BUY3 & 0.858 & & & \\
\hline
\end{tabular}


Third, a confirmatory factor analysis (CFA) indicates the convergence and discriminant validity using AMOS 21. Composite reliability (CR) of each construct was greater than 0.7 , hence ensuring the internal consistency reliability of the survey. Average variance extracted (AVE) values of all constructs exceeded 0.5, ensuring convergent validity (see Table 2). As noted in Table 3, the square root of each construct's AVE was higher than other correlations among the variables, therefore reflecting the evidence of satisfactory discriminant validity.

Structural equation modeling (SEM) was applied to assess the hypothesized model. Firstly, multiple fit indices including Chi-square value and its associated degrees of freedom $\left(X^{2} / \mathrm{df}\right)$, Comparative Fit Index (CFI), Normed Fit Index (NFI), Goodness-ofFit Index (GFI), Average Goodness-of-Fit Index (AGFI), Tucker-Lewis Index (TLI), the Root Mean Square Error of Approximation (RMSEA) provided the assessment of model fit (see Table 4).

Table 3: Correlation Matrix and Square Root of the AVE

\begin{tabular}{lcccccccccc}
\hline & ADV & PCO & CON & SOC & ENT & IRR & VAL & USE & SAT & BUY \\
\hline ADV & 0.80 & & & & & & & & & \\
PCO & 0.16 & 0.82 & & & & & & & & \\
CON & 0.05 & 0.32 & 0.79 & & & & & & & \\
SOC & 0.05 & 0.41 & 0.39 & 0.91 & & & & & & \\
ENT & 0.02 & 0.04 & 0.10 & 0.03 & 0.86 & & & & & \\
IRR & -0.07 & -0.30 & -0.43 & -0.46 & -0.04 & 0.91 & & & & \\
VAL & 0.17 & 0.41 & 0.61 & 0.44 & 0.03 & -0.46 & 0.90 & & & \\
USE & 0.03 & 0.40 & 0.49 & 0.44 & 0.07 & -0.33 & 0.66 & 0.89 & & \\
SAT & 0.12 & 0.40 & 0.42 & 0.44 & 0.06 & -0.31 & 0.39 & 0.63 & 0.88 & \\
BUY & 0.15 & 0.59 & 0.53 & 0.63 & 0.06 & -0.52 & 0.54 & 0.59 & 0.58 & 0.88 \\
\hline
\end{tabular}

Notes: The square roots of AVEs are reported on the diagonal, ADV: Advertising perception, PCO: Perceived contextualization, CON: Content quality, SOC: Social involvement, ENT: Entertainment, IRR: Irritation, VAL: perceived value, USE: Continuance intention, SAT: Satisfaction, BUY: Buying inclination.

Table 4: Fit Indices for Research Model

\begin{tabular}{lccc}
\hline \multicolumn{1}{c}{ Index } & $\begin{array}{c}\text { Recommended } \\
\text { Criteria }\end{array}$ & $\begin{array}{c}\text { Measurement } \\
\text { Model }\end{array}$ & Structure Model \\
\hline$X^{2} / \mathrm{df}$ & $<2$ & 1.246 & 1.580 \\
CFI & $>0.9$ & 0.986 & 0.966 \\
NFI & $>0.9$ & 0.935 & 0.914 \\
GFI & $>0.9$ & 0.907 & 0.885 \\
AGFI & $>0.8$ & 0.883 & 0.861 \\
TLI & $>0.9$ & 0.984 & 0.962 \\
RMSEA & $<0.08$ & 0.028 & 0.044 \\
\hline
\end{tabular}

\section{Evaluation of Structural Model}

First, advertising value is explained $50.6 \%$ by five factors (i.e., ADV, PCO, CON, SOC and IRR) in the research model. The hypotheses of advertising perception $(\beta=0.106$; $\mathrm{p}<0.05)$, contextualization $(\beta=0.167$; $\mathrm{p}<0.001)$, content quality $(\beta=0.444$; $\mathrm{p}<$ 
$0.001)$, social involvement $(\beta=0.149 ; \mathrm{p}<0.001)$ and irritation $(\beta=-0.152 ; \mathrm{p}<0.001)$ have significant influences on perceived value. Nonetheless, entertainment does not significantly influence perceived value. Thus, hypotheses H1, H2, H3, H4 and H6 are supported, whereas H5 is not supported.

Second, satisfaction is explained by $17.4 \%$ of the variation in the research model. Perceived value $(\beta=0.417 ; \mathrm{p}<0.001)$ significantly positive affects satisfaction, therefore supporting $\mathrm{H} 7$.

Third, continuance intention is explained by $60 \%$ of the variation in the research model. Perceived value $(\beta=0.495 ; \mathrm{p}<0.001)$ and satisfaction $(\beta=0.424 ; \mathrm{p}<0.001)$ positively influence continuance intention, hence supporting $\mathrm{H} 8$ and $\mathrm{H} 10$.

Lastly, buying inclination is explained by $46.8 \%$ of the variation in the research model. Perceived value $(\beta=0.392 ; p<0.001)$ and satisfaction $(\beta=0.420 ; p<0.001)$ significantly influence continuance intention, thus supporting $\mathrm{H} 9$ and $\mathrm{H} 11$.

Table 5: Hypotheses Results

\begin{tabular}{llllll}
\hline Hypothesis & Path & $\boldsymbol{\beta}$ & t-value & p-value & Results \\
\hline H1 & ADV $\rightarrow$ VAL & 0.106 & $2.143^{*}$ & 0.032 & Accepted \\
H2 & PCO $\rightarrow$ VAL & 0.167 & $3.009^{* *}$ & 0.003 & Accepted \\
H3 & CON $\rightarrow$ VAL & 0.444 & $7.067^{* * *}$ & 0.000 & Accepted \\
H4 & SOC $\rightarrow$ VAL & 0.149 & $2.628^{* *}$ & 0.009 & Accepted \\
H5 & ENT $\rightarrow$ VAL & 0.038 & $0.808^{(n . s)}$ & 0.419 & Rejected \\
H6 & IRR $\rightarrow$ VAL & -0.152 & $-2.704^{* *}$ & 0.007 & Accepted \\
H7 & VAL $\rightarrow$ SAT & 0.417 & $6.997^{* * *}$ & 0.000 & Accepted \\
H8 & VAL $\rightarrow$ USE & 0.495 & $9.496^{* * *}$ & 0.000 & Accepted \\
H9 & VAL $\rightarrow$ BUY & 0.392 & $7.059^{* * *}$ & 0.000 & Accepted \\
H10 & SAT $\rightarrow$ USE & 0.424 & $0.820^{* * *}$ & 0.000 & Accepted \\
H11 & SAT $\rightarrow$ BUY & 0.420 & $7.414^{* * *}$ & 0.000 & Accepted \\
\hline
\end{tabular}

Notes: ${ }^{*} \mathrm{p}<0.05 ; * * \mathrm{p}<0.01 ; * * * \mathrm{p}<0.001 ;$ n.s: not significant

Figure 2: Structural Model Results

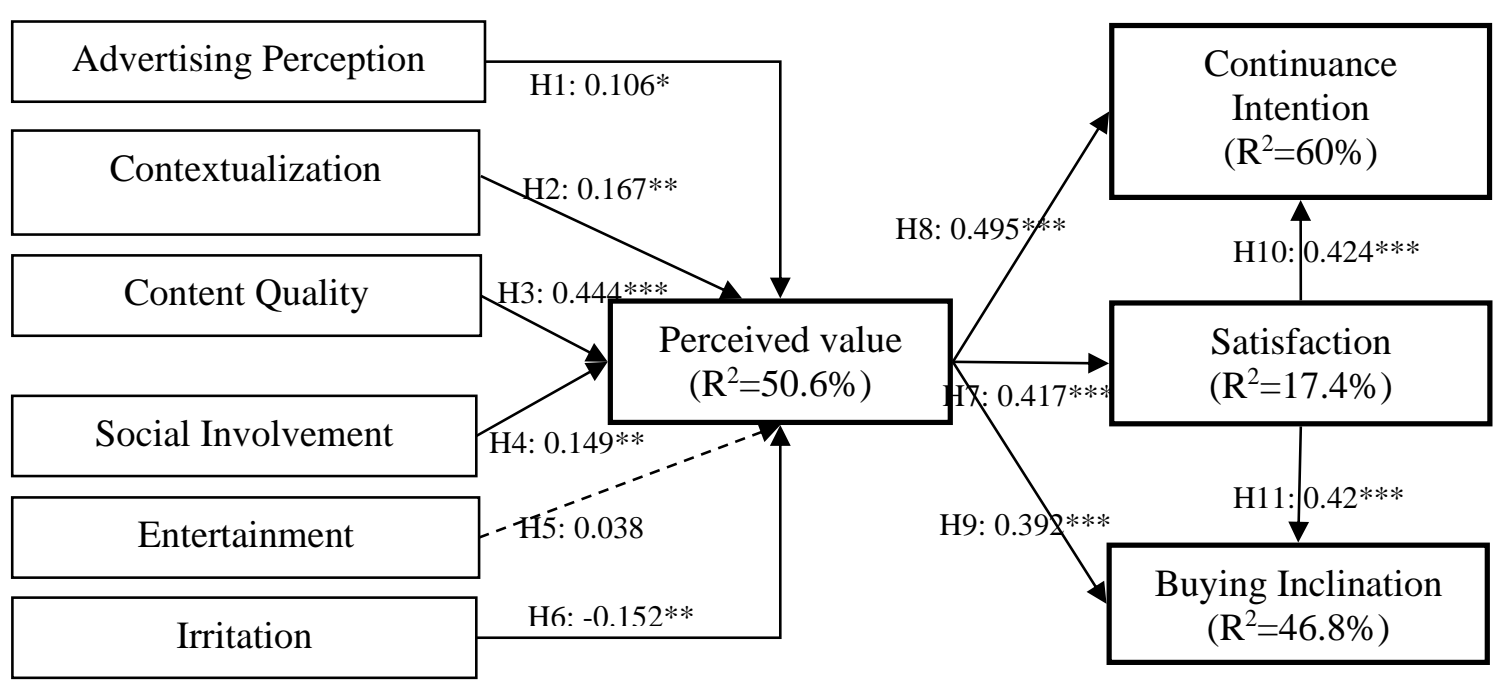




\section{Discussion}

Foremost, the impacts of factors on perceived value are revealed. The majority of factors, except for entertainment, have significant influences on consumers' favorable perceptions in LBAs. Whereas content quality is the most significant factor driving perceived value, the lowest important indicator comes from advertising perception (see Table 5 and Figure 2).

The positive correlation between advertising perception and perceived value is investigated. It implies that consumers' thoughts and positive perceptions depend on advertising cognitions. An advertisement makes different from others when consumers realize its reality, transparence that advertisers create. This result is consistent with previous findings in SMS advertising (Bakr et al., 2019) and digital advertising (Stewart et al., 2018). The results show that contextualization positively impacts perceived value. It implies that context awareness of time and place is integrated to reinforce LBA effectiveness. This outcome is aligned with past conclusions (Feng et al., 2016). In addition, content quality has a significant, positive effect on advertising value. Generally speaking, advertising content is more accurate, timely and relevant to consumers' interests, they would be likely to exhibit favorable perceptions of LBAs. This investigation adds the reasonable evidence for prior studies (Cheng, 2020; Park, 2020). Otherwise, the result reveals that social involvement influences positively perceived value. It hints that consumers' cognition of advertising value is positive if they catch more valuable information about advertised products/services via communications with other people such as relatives, friends and colleagues who offer mental supports rather than physical, financial assistance. This result is supportive to extant studies (Wang and Genç, 2019). Hence, the close relationship between organizations and target consumers should be formed before, during and after the process of dispersing advertisements. Regarding emotional dimensions, irritation is explored to negatively affect favorable judgment toward LBAs, whilst the correlation between entertainment and advertising value is non-significant. This result is contrary with our prediction and prior investigations (Lin and Bautista, 2020). It is probably explained that entertainment characterizes emotions, feelings and sentiments of each user via their experience rather than the achievement of pre-specific goals toward LBA adoption (Teng, 2018). Another reason is that other advertisements (e.g., mobile advertising and digital advertising) might receive more favorable perceptions than LBAs in the growing stage. Therefore, some possible reasons lead to minor contribution of emotional motivation to perceived value. Otherwise, this study strongly supports the negative relationship between irritation and perceived value in the extant research (Lin and Bautista, 2020), but this exploration is dissimilar from past research on smartphone advertising (Kim and Han, 2014). It interprets that the provision of enormous amount of information as well as the message dispensation more frequently over consumers' control cause displeasing, annoyed statement. However, the value of this relationship is relatively high in this research and compared to extant studies (Lin and Bautista, 2020) because technology-advanced countries such as Singapore, Japan, Korea and China where promulgate more comprehensive, stringent legislative framework than Vietnam enable consumers to reach more control over LBAs or their consents before receiving it. 
On the other hand, the findings indicated the positive relationships amongst perceived value, satisfaction, continuance intention and buying inclination. First, perceived value gives an important reason for continuation to use LBAs. This is in the line of previous studies on mobile services (Kuo et al., 2009) and mobile advertising (Hsiao and Chang, 2014). This contribution means that if advertising value does not meet customer needs and interests, they display the feeling of dissatisfaction with these advertisements. Consequently, this will prevent them from adopting continuance intention toward LBAs. Moreover, advertising value is investigated to promote satisfaction with LBAs, which is consistent with previous arguments (Chan et al., 2016). Moreover, perceived value and satisfaction are explored to be crucial predictors of purchase intention. Not surprisingly, the positive impacts of perceived value and satisfaction on buying inclination convince firmly both advocates and skeptics (Nguyen, 2021; Martins et al., 2019). Therefore, it is necessary for marketers to increase favorable assessment and pleasantness of consumers by boosting LBA's utility and its benefits. Also, when the usage of LBAs provokes consumers' positive evaluation, they are likely to adopt intention to purchase advertised products/services. Lastly, the result illustrates the positive relationship between satisfaction and continuance intention. This is similar with extant studies in mobile instant messaging (Oghuma et al., 2016) and mobile advertisement (Hsiao and Chang, 2014).

\section{Conclusion and Further Research Directions}

LBA has caught considerable attention from both industrial and academic sides. This paper portrays a holistic insight into how perceived LBA value is formulated and its effect on satisfaction and behavioral intentions. Based on the well-established Choice Value Model, a hypothetical model is framed to systematically test the influence of important antecedents on perceived value. Furthermore, the importance of perceived value for strengthening satisfaction, continuance intention and buying inclination is stressed in the LBA literature. Satisfactory feelings also drive significantly continuous use and evoke shopping actions to advertised brands. This research remains delving more meaningful findings relating LBA literature and practical value. Furthermore, the findings support marketers to tailor efficient marketing strategies and implement advertising campaigns in an emerging market like Vietnam.

Some limitations are acknowledged. First, additional variables need to be employed in future studies. Although the value of $\mathrm{R}^{2}=50.6 \%$ implies the explanation of five factors for perceived value, it is insightful to recruit different motivators of perceived value in the LBA context. Second, this study's failure is to consider entertainment for driving advertising value in the growing stage of LBAs. Hence, promising studies are warranted to re-examine the research model to unveil the significance of this variable. The last limitation is the sample size and survey population (confining to majority of students in universities). Future research should be encouraged to increase the number of respondents in the survey and to generalize existing model to various segments of mobile users. 


\section{Implications for Asian Business}

\section{Theoretical Implications}

Regarding a theoretical standpoint, this research offers several major contributions to LBA literature. First, the identification of crucial factors determines perceived advertising value. Contextualization, content quality and social involvement are concluded as the most important antecedents of perceived value. Specially, the exploration disclosed that the utility of LBAs relies greatly on contextualization. This makes different from previous studies in mobile advertising and other advertising forms. Otherwise, consumers' appreciation of perceived value is revealed due to the strong navigation of social role when it helps consumers to absorb more acquired information about brands and other's shopping experience, and provokes their enthusiasm to display positive behavioral responses. Furthermore, our research agrees strongly the most substantial contribution of content quality to perceived value. Basically, this study follows the existing LBA literature and remains validity based on the CVM.

Otherwise, this work substantiated that perceived value is a central determinant of satisfaction, continuance intention and buying inclination. Albeit extant studies have empirically conducted to explore the close link between perceived value and buying inclination in LBAs, not much research has examined whether perceived value stimulates satisfaction and continuance intention. Additionally, the findings of this study are worthy when satisfaction is affirmed as a key predictor of post-intentions. Generally speaking, this study casted light on how advertising effectiveness is shaped based on the motivations underlying perceived value, satisfaction and behavioral intentions in LBAs.

\section{Practical Implications}

Regarding a practical standpoint, the findings offer an in-depth understanding of how to develop effective advertising strategies via accounting for a mechanism of perceived value, satisfaction and behavioral intentions (including continuance intention and buying inclination) toward LBAs in Vietnam and in the Asian area.

First, innovative marketers and advertisers should focus primarily on contextualization through advanced technological infrastructure and location positioning technology. It is important to deliver advertising messages to targeted customers by identifying adequate real-time (when), relevant place of consumers nearby vendors (where) and target objects (who). In order to address this issue, the improvement in technological platforms and contextualized technologies is essential for marketers and advertisers. Second, marketers and advertisers ensure that qualified, relevant and sufficient information is conveyed to designated consumers based on their necessity, wants and preferences. Hence, if customers receive proper advertising content, they would express less irritation and heighten value LBA perceptions. Additionally, marketers and practitioners need to make considerable effort to disseminate information content to each customers in various ways. For example, the plethora of LBAs such as EMS, MMS and mobile applications need to be used to provide their substitutes, optimize information display, and suit a wide range of mobile phones. This enables advertisers to increase their concentration, reduce time waste and curb irritation. Third, marketers 
and advertisers should be better off to regard the encouragement of social individuals surrounding customers. Marketers should focus on enlarging social relationships by developing important communication channels that consumers use frequently and interact with individuals and firms such as mobile social media platforms (e.g., Facebook, Instagram and Tiktok). This is an imperative requirement for raising user awareness and encouraging them to participate actively in LBAs because based on the current context of an orient culture in Vietnam, individuals rely heavily on others' lifestyle, thoughts and influences. Moreover, incredible people need to be employed in the LBA campaigns because customers who view advertisements and receive recommendations from these influencers intend to follow their references and behaviors, and purchase advertised brands (Le and Wang, 2021). Fourth, the importance of advertising perception in motivating advertising value suggests that marketers and advertisers should create LBAs that attract customers' attention. They focus on developing user-friendly interface and better designed advertising layouts that provide customers with interesting experience in LBAs.

Furthermore, based on a mechanism of behavioral intentions from a consumer perspective, marketers and advertisers should endeavor to know consumers' expectations, the change of sentiments, feelings and behavioral exhibition. Managers should establish and adapt safeguard policies and the guidance to enhance consumers' beliefs, credibility, and ensure their interests and rights for the usage of their personal information based on position-detecting technologies. Moreover, marketers and advertisers need to concentrate on young users to become the major customer segment because they can be willing to embrace LBAs, and become a connective means with the community to diffuse quickly these advertisements to other people. Overall, this study offers managers and marketers in an emerging market (e.g., Vietnam) and Asia Pacific region strategic and managerial guidelines to resolve efficiently current issues of advertising effectiveness based on the investigations of advertising value, satisfaction and behavioral intention toward LBAs.

\section{References}

Appota, (2018), "Vietnam mobile app market report 2018", available at: https://appota.com/uploads/report/Vietnam_mobile_app_market_Report_2018_EN.pd $\mathrm{f}$ (accessed 20 June 2020).

Asnakew, Z. S. (2020), "Customers' continuance intention to use mobile banking: Development and testing of an integrated model", The Review of Socionetwork Strategies, vol. 14 no. 1, pp.123-146.

Bakr, Y., Tolba, A., \& Meshreki, H. (2019), "Drivers of SMS advertising acceptance: a mixedmethods approach", Journal of Research in Interactive Marketing, vol. 13 no. 1, pp.96118.

Bankmycell, (2019), "How many phones are in the world?", available at: https://www.bankmycell.com/blog/how-many-phones-are-in-the-world (accessed 12 June 2021).

Beltramini, R. F. (1988), "Perceived believability of warning label information presented in cigarette advertising", Journal of Advertising, vol. 17 no. 2, pp.26-32.

Bhattacherjee, A. (2000), "Acceptance of e-commerce services: The case of electronic brokerages", Transactions on Systems, Man, and Cybernetics, vol. 30 no. 4, pp.411420. 
Bhattacherjee, A. (2001), "Understanding information systems continuance: An expectationconfirmation model", MIS Quarterly, vol. 25 no. 3, pp.351-370.

Calder, B. J., Malthouse, E. C., \& Schaedel, U. (2009), "An experimental study of the relationship between online engagement and advertising effectiveness", Journal of Interactive Marketing, vol. 23 no. 4, pp.321-331.

Chan, S. F., Barnes, B. R., \& Fukukawa, K. (2016), "Consumer control, dependency and satisfaction with online service", Asia Pacific Journal of Marketing and Logistics, vol. 28 no. 4, pp.594-615.

Cheng, Y.-M. (2020), "Quality antecedents and performance outcome of cloud-based hospital information system continuance intention", Journal of Enterprise Information Management, vol. 33 no. 3, pp.654-683.

Deng, Z., Liu, S., \& Hinz, O. (2015), "The health information seeking and usage behavior intention of Chinese consumers through mobile phones", Information Technology \& People, vol. 28 no. 2, pp.405-423.

Ducoffe, R. H. (1995), "How consumers assess the value of advertising", Journal of Current Issues and Research in Advertising, vol. 17 no. 1, pp.1-18.

Feng, X., Fu, S., \& Qin, J. (2016), "Determinants of consumers' attitudes toward mobile advertising: The mediating roles of intrinsic and extrinsic motivations", Computers in Human Behavior, vol. 63 no. pp.334-341.

Gan, C., \& Wang, W. (2017), "The influence of perceived value on purchase intention in social commerce context", Internet Research, vol. 27 no. 4, pp.772-785.

Ha, Y. W., Park, M.-C., \& Lee, E. (2014), "A framework for mobile SNS advertising effectiveness: user perceptions and behaviour perspective", Behaviour \& Information Technology, vol. 33 no. 12, pp.1333-1346.

Handayani, P. W., Hidayanto, A. N., Pinem, A. A., Hapsari, I. C., Sandhyaduhita, P. I., \& Budi, I. (2017), "Acceptance model of a Hospital Information System", International Journal of Medical Informatics, vol. 99 no. pp.11-28.

Heijden, H. (2004), "User acceptance of hedonic information systems", MIS Quarterly, vol. 28 no. 4, pp.695-704.

Heitzmann, C. A., \& Kaplan, R. M. (1988), "Assessment of methods for measuring social support", Health Psychology, vol. 7 no. 1, pp.75-109.

Hsiao, W.-H., \& Chang, T.-S. (2014), "Understanding consumers' continuance intention towards mobile advertising: A theoretical framework and empirical study", Behaviour \& Information Technology, vol. 33 no. 7, pp.730-742.

Hsu, C.-L., \& Lin, J. C.-C. (2016), "Effect of perceived value and social influences on mobile app stickiness and in-app purchase intention", Technological Forecasting and Social Change, vol. 108 no. pp.42-53.

Huang, L., Mou, J., Koong, K. S., \& Du, Y. (2019), "An investigation of perceived value dimensions: implications for mobile marketing research", International Journal of Mobile Communications, vol. 17 no. 6, pp.641-681.

Joo, Y. J., Park, S., \& Shin, E. K. (2017), "Students' expectation, satisfaction, and continuance intention to use digital textbooks", Computers in Human Behavior, vol. 69 no. pp.8390.

Kim, Y. J., \& Han, J. Y. (2014), "Why smartphone advertising attracts customers: A model of web advertising, flow, and personalization", Computers in Human Behavior, vol. 33 no. pp.256-269.

Kuo, Y.-F., Wu, C.-M., \& Deng, W.-J. (2009), "The relationships among service quality, perceived value, customer satisfaction, and post-purchase intention in mobile valueadded services", Computers in Human Behavior, vol. 25 no. 4, pp.887-896.

Le, X. C. (2021), "Charting sustained usage toward mobile social media application: the criticality of expected benefits and emotional motivations", Asia Pacific Journal of Marketing and Logistics, doi: 10.1108/APJML-11-2020-0779 
Le, X. C., \& Wang, H. (2020), "Context-aware and social integrative-related factors as the precursors of efficient context aware advertising via mobile applications", International Journal of Mobile Communications, pp.1-17, doi: 10.1504/IJMC.2022.10035486.

Le, X. C., \& Wang, H. (2021), "Integrative perceived values influencing consumers' attitude and behavioral responses toward mobile location-based advertising: An empirical study in Vietnam", Asia Pacific Journal of Marketing and Logistics, vol. 33 no. 1, pp.275-295.

Leung, L., \& Chen, C. (2019), "E-health/m-health adoption and lifestyle improvements: Exploring the roles of technology readiness, the expectation-confirmation model, and health-related information activities", Telecommunications Policy, vol. 43 no. 6, pp.563-575.

Lin, T., \& Bautista, J. R. (2020), "Content-related factors influence perceived value of locationbased mobile advertising", Journal of Computer Information Systems, vol. 60 no. 2, pp.184-193.

Lin, T., Paragas, F., \& Bautista, J. R. (2016), "Determinants of mobile consumers' perceived value of location-based mobile advertising and user responses", International Journal of Mobile Communications, vol. 14 no. 2, pp.99-117.

Magni, M., Susan Taylor, M., \& Venkatesh, V. (2010), "'To play or not to play': A crosstemporal investigation using hedonic and instrumental perspectives to explain user intentions to explore a technology", International Journal of Human-Computer Studies, vol. 68 no. 9, pp.572-588.

Martins, J., Costa, C., Oliveira, T., Gonçalves, R., \& Branco, F. (2019), "How smartphone advertising influences consumers' purchase intention", Journal of Business Research, vol. 94 no. pp.378-387.

Merisavo, M., Kajalo, S., Karjaluoto, H., Virtanen, V., Salmenkivi, S., Raulas, M., \& Leppäniemi, M. (2007), "An empirical study of the drivers of consumer acceptance of mobile advertising", Journal of Interactive Advertising, vol. 7 no. 2, pp.41-50.

Morimoto, M., \& Chang, S. (2006), "Consumers' attitudes toward unsolicited commercial email and postal direct mail marketing methods", Journal of Interactive Advertising, vol. 7 no. 1, pp.1-11.

Nguyen, G. N. (2021), "Resistance to Change and Purchase Intention of Electric Vehicles: Empirical evidence from Vietnam", Asian Journal of Business Research, vol. 11 no. 2, pp.83-101.

Nguyen, T. H., \& Le, X. C. (2021), "How social media fosters the elders' COVID-19 preventive behaviors: perspectives of information value and perceived threat", Library Hi Tech, vol. 39 no. 3, pp.776-795.

Nysveen, H., Pedersen, P. E., \& Thorbjørnsen, H. (2005), "Intentions to use mobile services: Antecedents and cross-service comparisons", Journal of the Academy of Marketing Science, vol. 33 no. 3, pp.330-346.

Oghuma, A. P., Libaque-Saenz, C. F., Wong, S. F., \& Chang, Y. (2016), "An expectationconfirmation model of continuance intention to use mobile instant messaging", Telematics and Informatics, vol. 33 no. 1, pp.34-47.

Oliver, R. L. (1980), "A cognitive model of the antecedents and consequences of satisfaction decisions", Journal of Marketing Research, vol. 17 no. 4, pp.460-469.

Omigie, N. O., Zo, H., Rho, J. J., \& Ciganek, A. P. (2017), "Customer pre-adoption choice behavior for M-PESA mobile financial services", Industrial Management \& Data Systems, vol. 117 no. 5, pp.910-926.

Park, T. (2020), "How information acceptance model predicts customer loyalty? A study from perspective of eWOM information", The Bottom Line, vol. 33 no. 1, pp.60-73.

Petty, R. E., \& Cacioppo, J. T. (1986), Communication \& persuasion: Central \& peripheral routes to attitude change, New York: Springer-Verlag.

Poromatikul, C., De Maeyer, P., Leelapanyalert, K., \& Zaby, S. (2020), "Drivers of continuance intention with mobile banking apps", International Journal of Bank Marketing, vol. 38 no. 1, pp.242-262. 
Sheth, J. N., Newman, B. I., \& Gross, B. L. (1991), "Why we buy what we buy: A theory of consumption values", Journal of Business Research, vol. 22 no. 2, pp.159-170.

Slater, M. D., \& Rouner, D. (1996), "How message evaluation and source attributes may influence credibility assessment and belief change", Journalism \& Mass Communication Quarterly, vol. 73 no. 4, pp.974-991.

Sreelakshmi, C. C., \& Sangeetha, K. P. (2020), "Continuance adoption of mobile-based payments in Covid-19 context: An integrated framework of health belief model and expectation confirmation model", International Journal of Pervasive Computing and Communications, vol. 16 no. 4, pp.351-369.

Statista, (2021), "Number of smartphone users worldwide from 2016 to 2026", available at: https://www.statista.com/statistics/330695/number-of-smartphone-users-worldwide/ (accessed 20 June 2021).

Stewart, K., Kammer-Kerwick, M., Koh, H. E., \& Cunningham, I. (2018), "Examining digital advertising using an affect transfer hypothesis", Journal of Research in Interactive Marketing, vol. 12 no. 2, pp.231-254.

Teng, W. (2018), "Utilitarian, hedonic, collecting, epistemic, and high values as determinants of the attractiveness of premium promotions", Journal of Marketing Communications, vol. pp.1-19.

Thaichon, P., Quach, S., \& Surachartkumtonkun, J. (2019), "Intention to Purchase at a Fast Food Store: Excitement, Performance and Threshold Attributes", Asian Journal of Business Research, vol. 9 no. 1, pp.81-101.

Tsang, M. M., Ho, S.-C., \& Liang, T.-P. (2004), "Consumer attitudes toward mobile advertising: An empirical study", International Journal of Electronic Commerce, vol. 8 no. 3, pp.65-78.

Venkatesh, V., \& Davis, F. D. (2000), "A theoretical extension of the Technology Acceptance Model: Four longitudinal field studies", Management Science, vol. 46 no. 2, pp.186204.

Wang, Y., \& Genç, E. (2019), "Path to effective mobile advertising in Asian markets: Credibility, entertainment and peer influence", Asia Pacific Journal of Marketing and Logistics, vol. 31 no. 1, pp.55-80.

Wong, S.-M., Leong, C., \& Puah, C.-H. (2020), "Mobile Internet adoption in Malaysian suburbs: The moderating effect of gender", Asian Journal of Business Research, vol. 9 no. 3, pp.90-114.

Zhu, D. H., Sun, H., \& Chang, Y. P. (2017), "How the content of location-based advertisings influences consumers' store patronage intention", Journal of Consumer Marketing, vol. 34 no. 7, pp.603-611. 